\title{
New Dimensions in Code-Mixing and the Sri Lankan \\ Case:
}

\author{
An Exploratory Study
}

Indira J Mawelle $(\mathrm{PhD})$

\author{
Senior Lecturer, Department of English and Linguistics \\ University of Sri Jayewardenepura
}

\begin{abstract}
Code-switching and code-mixing, two by-products of language contact situations, are widely used linguistic strategies, not only in informal conversational contexts but also in the informal media discourse. The reasons hitherto applicable for the mixing of codes seem non-relevant in some code-mixing situations today. This is true to certain segments of the Sri Lankan media context, too, in that the popular Sri Lankan commercial broadcasting media is accused by prescriptivist groups of making excessive use of code-mixing. The purpose of this paper is to synthesize and explore the seminal research articles available in the field of code alternation so as to better understand the Sri Lankan situation of code-switching and code-mixing, as practiced by its general bilingual populations and by the popular commercial media channels.
\end{abstract}

\section{Introduction}

The origin of the term 'code-switching' lies in the communication sciences, but with a different meaning (Bullock and Toribio 2009: xixii). According to Fries and Pike (1949) the term 'code' has been originally borrowed from the subject of communication technology where the term 'code-switching' is used to refer to "a mechanism for the unambiguous transduction of signals between systems" (Gardner- 
Chloros, 2009: 11). In linguistics and bilingual studies, however, the terms 'code-switching' and 'code-mixing' are used to refer to the practice of alternating between two languages or two language varieties in verbal interaction. This includes switching and/or mixing between languages, dialects, or even between different styles and registers within the same language (Coupland, 1984).

Language contact situations can be resultant in processes such as borrowing, pidginization, language death (Gardner-Chloros, 2009:4), language shift, lingua francas, multilingualism (Trudgill, 1992: 45) and linguistic alternation which includes code-switching and code-mixing. Linguistic alternation may take place inter-sententially or intrasententially, within the same conversation, and in an unchanged setting. This phenomenon may also include intra-word alternation which is a linguistic change-over within a word (for example, the alternation at a morpheme boundary) and tag-switching, or the substitution of a tagword/phrase of one language with that of another, which is commonly considered as one manifestation of intra-sentential language alternation, or code-mixing.

The surveying of the most influential findings in the area of code alternation was attempted in this research paper as a step towards highlighting the practice of code-mixing on Sinhala-medium commercial broadcasting media, which is a less-researched area in the field of code-switching and code-mixing. 


\section{Research Problem}

There is vehement criticism from the prescriptivist groups of Sri Lanka towards the Sinhala-medium private commercial broadcasting media practice of what they refer to as 'excessive', 'degenerative', 'defective', mixing of codes between Sinhala and English that has now spread into certain segments of media audiences among whom it has become a 'fashion'. The frequency and the way in which these audiences, particularly consisting of youth groups, have adopted and continue the use of these new forms of code-mixing in their daily conversations, appear to be resisting the accusations directed at this linguistic behavior as a superficial verbal strategy used merely for language display.

\section{Research Methodology}

Since the objective of the present paper was to identify and communicate the seminal information and trends pertaining to the topic of code-alternation in research world-wide so as to shed better light on the Sri Lankan code-mixing situation, the literature survey method has been used. In this attempt, the seminal research articles available in the field of code alternation have been explored so as to better understand the Sri Lankan situation of code-switching and code-mixing.

\section{Available Definitions on Code-Switching and Code-Mixing}

A survey of literature on the use of two or more languages in conversation reveals lack of consensus on the part of researchers working in the field, with regard to the definitions of the terms 'codeswitching' and 'code-mixing'. While some researchers use the term 'code-switching' to encircle all types of language alternating behaviour which includes code-mixing as a distinct sub-category of code- 
switching, others tend to use the two terms interchangeably. There are yet others who opt for altogether different terms for the different phenomena involved. Clyne (2003: 75) for instance, uses the term codeswitching for the transference of single lexical items from one language to another while suggesting the term 'transversion' to refer to instances where speakers completely switch over from one language into another while in conversation. For Kachru (1978: 28) code-mixing is "the use of one or more languages for consistent transfer of linguistic units from one language to another". 'Code-switching' is the term Myers-Scotton (1993: 1) uses to define "the alternation of linguistic varieties within the same conversation". Myers-Scotton (1993: 1) further remarks that "[i]n bilingual communities, fluent bilinguals sometimes engage in codeswitching by producing discourses which, in the same conversational turn or in consecutive turns, include morphemes from two or more of the varieties in their linguistic repertoire". Auer (1999), though originally prefers the term 'code-alternation' to refer to the linguistic behaviour concerned, defines code-switching from the perception of the interlocutor when he says that it is a state where the participants in a verbal interactional episode tend to regard the juxtaposition of two languages as locally meaningful. Hymes (1974) uses the term codeswitching as "a common term for the alternative use of two languages, varieties of a language or even speech styles".

Muysken (2000) is one among the many researchers who are in agreement with the claim that code-mixing is a type of linguistic behavior which falls under the broader area of code-switching. $\mathrm{He}$ (Muysken, 2000: 1) makes a distinction between code-switching and code-mixing, and suggests the appropriateness of the term 'code- 
mixing' for intra-sentential code-switching "where lexical items and grammatical features from two languages appear in one sentence". In Muysken's view intra-sentential "insertions at the word-level" are similar to "spontaneous borrowings" (cited in Bennett-Kastor, 2008: 32 ), but he at the same time observes the difficulty of distinguishing between loan words/borrowings and spontaneous borrowings or insertions. Wray, Trott and Bloomer (1998: 96), too, distinguish between code-switching and code-mixing when they use the same term (as Muysken) 'code-mixing' to refer to the situation of a bilingual speaker mixing languages within a sentence. Noteworthy is the emphasis of Wray, Trott and Bloomer (1998) on the intra-sentential aspect of code-mixing. Gardener-Chloros (2009: 12) argues that loan words or borrowings "start off as code-switches and then gradually become established as loans".

According to Trudgill (1992: 6) the linguistic behaviour of bilingual or bidialectal speakers crossing over to and from one language or dialect and another within the same conversation is given the term 'codeswitching, and the act of code-switching between languages "with such rapidity and density, even within sentences and phrases, that it is not really possible to say at any given time which language they are speaking" is termed 'code-mixing'. Trudgill's definition of code-mixing thus incorporates a switch of languages/codes within a sentence whereas his definition of code-switching could be comprehended as referring to code-changing at phrase or sentence boundaries. However, the argument for the existence of a 'dominant language' in code-switching as perceived in conducting the survey of literature, appears to stand in contrast to Trudgill's assertion of the difficulty in distinguishing between the two languages involved in a code-mixed situation. The 
dominant/matrix language issue clearly emphasizes the existence of one language which provides the code-mixed utterance with its main structure on which elements of the other language are embedded.

Bokamba (1988), in his investigations into language variation among speakers of the Bantu languages, supports the view that code-switching takes place between sentence boundaries whereas code-mixing is to alternate codes within the sentence.

Code-switching is the mixing of words, phrases and sentences from two distinct grammatical (sub) systems across sentence boundaries within the same speech event ... Code-mixing is the embedding of various linguistic units such as affixes (bound morphemes), words (unbound morphemes), phrases and clauses from a co-operative activity where the participants, in order to infer what is intended, must reconcile what they hear with what they understand (Bokamba 1988).

McClure (1977: 97), in her studies on code alternation among bilingual Mexican-American children, defines code-mixing on similar lines when she claims that code-mixing occurs within the constituents of a sentence. For Kachru (1983) and Sridhar and Sridhar (1980), too, codeswitching takes place inter-sententially whereas code-mixing is an intrasentential occurrence.

Hudson (1980: 56) explains code-switching as a situation where a speaker "uses different varieties (of a language/languages) at different times". He speaks of a 'metaphorical code-switching' which is governed by the topic of conversation, while adopting the term 'conversational code-switching'. According to Hudson (1980: 57) metaphorical/situational 
code-switching involves registers that vary according to the topic of conversation, subject matter or the diglossic situation, and conversational code-switching occurs due to the speaker's aim of mixing two varieties in "roughly equal proportions ....in different parts of a single sentence". ${ }^{7}$ Although the term 'code-mixing' does not seem to appear in Hudson's discourse on language alternation, his use of the different terms and their explanations above could be conceived as indicating the recognition of a clear difference between inter-sentential and intra-sentential linguistic alternation. It could be argued out, however, that his claim for the appearance, in one sentence, of "roughly equal proportions" of the two languages concerned, cannot be applied to a majority of code-mixed situations. For instance, Poplack and Meechan's (1995) argument for the existence of a 'lexifier' language in code-switched utterances appear to stand contrary to Hudson's definition in that, according to Poplack and Meechan, there is always one language which supplies a code-switched utterance with more of its vocabulary.

Li (1997: 2), commenting on such linguistic alternation in HongKong, affirms that code-mixing is a sub-element of codeswitching.

Cantonese interspersed with English elements, especially single words, is generally referred to as mixed code, and the sociolinguistic phenomenon itself, code-mixing or (intra-sentential) code-switching (Li 1997: 2).

\footnotetext{
${ }^{7}$ According to Hudson (1980: 57) “(t)his balance may be achieved by expressing one sentence in one variety and the next one in the other, and so on, but it is equally possible for the two varieties to be used in different parts of a single sentence".
} 
Although opinion varies on what exact types of behaviour codeswitching and/or code-mixing includes, what becomes clear in most of the above definitions is that the term code-switching can be used as an umbrella term to cover all types of language alternation. Even intrasentential code-switching which may include the mere insertion of a single word, etc. is perceived as "a remarkable achievement on the part of bilingual speakers" (Sebba 2009: 40).

It is important to mention here that Alvarez-Caccamo (2002) points out that the term 'code-switching' and the formal discourse centred around it is, unlike concepts such as bilingualism and diglossia, still restricted to certain academic spheres, and needs to move out into the general public to generate interest in the linguistic behaviour concerned.

Although linguistic borrowing is sometimes compared with codeswitching/code-mixing, the two phenomena are not the same in that borrowed lexemes are used to fill the linguistic gaps which may occur in a language particularly due to cultural reasons. Thus, eventually, such borrowed lexemes become almost an inextricable part of the language which borrowed the item.

\section{Code-Switching and Code-Mixing as a Linguistic Strategy}

According to the traditional explanation of code-switching/code-mixing, speakers who have two or more languages at their disposal may, as driven by the speech situation, choose to mix those languages in their speech. They may particularly opt to do so in bilingual or multilingual settings where the conversational participants share two or more languages. Generally, code-switching "refers to instances when speakers switch between codes (languages or language varieties) in the course of 
a conversation (Swann et.al 2004: 40-41). As mentioned earlier, a formal distinction is sometimes made between intra-sentential codeswitching where switches occur within a sentence; and inter-sentential code-switching where a switch occurs at the boundary of a sentence. The term code-mixing is used "particularly for intra-sentential switching"8 (Swann et.al 2004: 41).

As Grosjean (1982) states, code-switching/code-mixing is a very common occurrence in bilingual speech. Gardner-Chloros (2009: 15) observes that sociolinguistic studies reveal that "people code-switch more, and more within the clause, when they are at ease, in informal situations (author's emphasis)". However, it has to be noted that there are also communities where code-switching/code-mixing is not used in informal settings but in formal occasions. For example, educated speakers of Arabic in Central Asia prefer to code-switch between a variety known as "oral educated Arabic" and their own local variety of Arabic, when they engage in formal verbal interactions such as being interviewed on television; the educated variety is used to indicate their education, and the local variety to express their loyalty to their roots (Abdul-Hassan, 1988). Hamam (2011: 41) draws an example from an episode on Al-Jazeera to show how diglossic code-switching can take place between standard Arabic and colloquial Arabic (i. e. the juxtaposition of fusha and ammiyya) to communicate messages that carry rhetorical or metaphorical values.

\footnotetext{
${ }^{8}$ However, a survey of literature on the use of two or more languages in conversation reveals lack of consensus on the part of researchers working in the field, with regard to the definitions of the terms 'code-switching' and 'code-mixing'.
} 
According to Bullock and Toribio (2009: 1) it may be quite common for certain segments of the people in any part of the world that tend to view the use of language from a "prescriptive" point of view to get agitated about a situation such as code-mixing. Muysken (2000: 1) views this attitude as being "so commonplace that the essential enrichment of having several grammars and lexicons participate in it at the same time is often seen as a threat, a disruption, a malady". As Muysken (2000: 1) notes, if this hostility towards code-switching/code-mixing has been observed among linguists, it has been by those researchers who belong to the "structuralist tradition in linguistics". For instance, Ronjat (1913) and Leopold (1939) who both come from the structuralist tradition, claim that bilingualism should be "tidy" (cited in Muysken, 2000: 1).

Although the structural linguistic point of view is thus, linguists in general tend to take a positive stance towards code-switching/codemixing as an indication of a bilingual's creativity. Kachru (1986), for instance, perceives the positive attributes of code-mixing; he sees it as a creative and an innovative process. He describes code-mixing as a productive outcome of the long-term contact of local languages with the colonizer-language in post-colonial societies where linguistic practices such as code-switching and code-mixing have become a necessary element in informal bilingual conversation.

Parakrama (1995), describing Auer's stand with regard to code alternation, endorses the viewpoint that code alternation adds to the creative aspect of speech: 
Auer (1995) supports this view-point when he states that the transfer of linguistic units, single or extended, does not hinder the creativity of linguistic production. What language alternation actually does, according to Auer is, to provide the bilingual speaker with additional support for creativity, productivity and more effective use of language in the transmission of his/her message. The most positive comment on code-switching/code-mixing could be that it is a 'legitimate style of informal talk' [my emphasis] (Parakrama 1995: 2).

Early research (of the mid 1970s) focused on the sociolinguistic functions served at a micro-level by the linguistic practice of code alternation. Thus it was postulated that code-switching and code-mixing are used by speakers as a discourse device for negotiating effective interpersonal communication. This would entail both the signaling and interpretation of speaker intentions. However, as it is also argued by researchers, bilinguals would often switch or mix varieties in order to convey messages which lie "beyond the superficial meaning of their words" (Gardener-Chloros, 2009). Thus, the practice of code alternation would also become an indication of the general values and norms in connection with the different varieties of language prevalent in a speech community (Bhatia \& Ritchie, 2004; Jakobson, 1990). A macro-level feature of linguistic alternation as identified by Poplack (1988) is that the values, beliefs and norms of a community plays a pivotal role in an individual's choice of language whereas factors such as one's own language proficiency and demographic variables come as secondary determiners. 
Sociolinguistic research has identified a set of common reasons which motivate linguistic alternation. According to these findings, a reason why bilinguals may alternate codes is at instances where the language being used does not have an appropriate word to express a particular concept (Grosjean 1982). Switching or mixing of codes may take place to adjust one's speech to the linguistic competencies and/or preferences of the other interlocutor/s in a speech situation (Giles \& Smith, 1979).

The topic of the conversation and its content, too, may determine if the speech event is carried out in one language or with language switches and/or mixes (Bhatia \& Ritchie, 2004). The age, level of education, social class, religion and gender of the participants in a conversation become contributing factors not only for the motivation of codeswitching/code-mixing, but also to determine the amount, frequency and the quality of such alternation. For instance, in many societies where alternation of codes is practised, it is the youth and/or the adolescents who tend to code-switch/code-mix more than the older generations of the community (Schmidt, 1985).

The general attitude which prevails in a society towards linguistic alternation, too, decides whether its speech community would opt or not for switching and/or mixing in their informal speech. The degree of power and prestige associated with a language also plays a dominant role in the choice of code by a bilingual conversational participant. The language of the majority population in migrant situations, or languages which are internationally recognized as those wielding power over other languages and language communities being chosen for switching and/or mixing purposes can be given as examples. 
Bilinguals may sometimes use code-switching/code-mixing according to the needs, preferences and linguistic competencies of the other interlocutors in a particular speech situation. For instance, Kim (2006) exemplifies that the employees in government offices in Canada express their greeting on answering the telephone using both the terms 'bonjour, hello', thus leaving space for the caller to continue the conversation in the language of his/her choice. Changing languages to accommodate the other speaker endows a bilingual speaker with a greater awareness of communicative sensitivity.

Appel and Muysken (2006) have observed six main functions served by code-switching/code-mixing, i.e. referential, directive, expressive, phatic, metalinguistic and poetic (Fong, 2011). Linguistic alternation is practiced by interlocutors specifically when they are confronted with the issue of language appropriateness. When one of their languages does not contain appropriate lexical items to express certain concepts, bilingual speakers switch over to the other language or mix codes to avoid misunderstanding and loss of intended meaning.

Fishman (2000), too, postulates that some topics make a bilingual more comfortable in switching or mixing codes because one of the languages at his/her disposal contains more specialized terms to deal with some topics. For example, Kurdish-Arabic bilinguals in a research conducted by Grosjean (1982) have expressed being more at ease when they mix codes on dealing with topics on politics and science. According to $\mathrm{Li}$ (1997) bilinguals code-mix/code-switch more when the discourse borders on topics centred around fashion, food and music. Lack of 
registral competence can also be a result of inadequate linguistic competence of some or all of the participants in a conversation.

Whether or not a bilingual speaker chooses to code-switch/code-mix could also depend on the mood of the speaker at the time of speaking. On such occasions, s/he may opt for words from the language in which $\mathrm{s} / \mathrm{he}$ is more comfortable and therefore, takes less of an effort to retrieve.

Habitual expressions such as greetings, requests, apologies and discourse markers may be used in the code-switched/code-mixed mode when speakers are more accustomed to using those expressions from the language other than the one in which they are communicating. For example, a majority of the monolingual, receiver bilingual or minimally bilingual groups of Sri Lanka retain the code-mixed utterances from the English language, such as 'Good Morning' (or just 'Morning'), 'Thank You', 'Sorry', Excuse Me' (for 'Please Excuse Me') in their verbal interactions carried out in their vernacular.

Code alternation is also used by bilinguals for other sociolinguistic reasons such as to signal a change of attitude, to cause humour or even to include or exclude someone from a conversation (Holmes 2001). Other variables such as social status and age would cause bilinguals to alternate codes. For example, pre-service teachers in the Emmanuel Alayande College of Education, Oyo, Oyo State and Ikere Ekiti College of Education, Ikere, in the code-switching/code-mixing research by Fakeye (2012), alternated between languages in the conversations with their colleagues but never did so in the verbal interactions with their lecturer. 
The switching or mixing of two languages is used heavily in advertisements to attract the attention of the audiences. In such instances, a major part of the advertisement contains the language with which the audiences are more familiar, while interspersing the advertisement with a small portion of very attractive words and/or phrases from the more privileged language. Languages are switched or mixed sometimes in the commercial mass media for the same reason of attracting, as well as for retaining audience attention. However, in Malaysia, code alternation in the fields of advertising and mass communication is considered as 'undisciplined' use of language which generates 'negative' attention from media audiences. The Malaysian government has banned code alternation on national television since it is perceived as contributing to the degradation of Malaysian national language and identity (Abu Bakar, 2009).

Kachru (1983), in his studies on language alternation in the Indian context where indicators of class and upward mobility play significant roles in the social life of individuals, has observed that code-mixing with English is used by speakers in India to reveal or conceal the social class to which they belong.

Some groups use code-mixing not only to establish an intra-group or a sub-group identity with their own characteristic patterns of code-mixing (cf. Tabouret-Keller, 1997) but also to project an invented identity of themselves on others. The social-psychology of this issue pertaining to the projection of identity can be explained further by applying Le Page and Tabouret-Keller's (1985) account on the identity factor on language choice: 
[T] he individual creates for himself the patterns of his linguistic behaviour so as to resemble those of the group or groups with which from time to time he wishes to be identified, or as to be unlike those from whom he wishes to be distinguished (Le Page and Tabouret-Keller 1985: 181).

Adetuyi, Akinghibe, Akinola, Ogunleye, and Omole (2011) have found in their research that a majority of the undergraduate students of the University of Ibadan mix and switch codes because the practice would earn them respect.

Above all the reasons and motivations discussed above, a person's position as a member of a group stands out in his/her choice to alternate codes (Fishman 2000). In as much as sociological and physiological factors such as an individual's age, sex, ethnic and religious background become important contributing factors in this regard, a speaker's "sociopsychological sense of reference group membership" (Kim, 2006: 53) also plays a significant role in the choice of language, thus projecting a social identity of oneself. According to Auer (1984) the use of two languages or parts of two languages in an unchanged speech situation, a speaker may project two identities at the same time, a privilege which a monolingual cannot enjoy. This is so because alternated codes signify shared values and experiences of a group or culture. Therefore, when speakers use words and phrases as they are found in the original languages, this practice endows that speaker with a sense of belonging to a particular group or culture. 
Code-Switching/Code-Mixing as a Verbal Strategy: Attitudes and Perspectives

The speech practice of code-switching gained prominence with Haugen's (1956) use of the term 'switching' to describe the action of crossing over between two languages in speech. However, codeswitching/code-mixing has traditionally been regarded as socially and linguistically deviant behaviour and a result of inadequate language proficiency (Heredia and Brown, forthcoming; Weinreich, 1953), thus disregarding its importance as a process which may cause, or precipitate, language change. Weinreich's (1953: 73) standpoint is that a stable bilingual alternates between languages according to "changes in the speech situation, but not in an unchanged speech situation and certainly not within a single sentence". It could be pointed out, however, that these views stand in stark contrast to the definitions and explanations of code-switching/code-mixing which emphasize the practice of alternation within unchanged speech situations, at times within the boundary of a single sentence.

The notion of code alternation as an inferior form of language use has been reiterated even by some who are known as seminal figures of modern linguistics, perhaps reflecting the negative attitudes of their time. Bloomfield (1927), for instance, strongly looks down upon the speech of a Native American informant, remarking on his proficiency as highly incompetent. 
White Thunder, a man around 40, speaks less English than Menomini, and that is a strong indictment, for his Menomini is atrocious. His vocabulary is small, his inflections are barbarous; he constructs sentences of a few threadbare models. He may be said to speak no language tolerably (Bloomfield 1927: 395)

The concept of 'semilingualism' thus reiterates the point that bilinguals who are inadequate in their linguistic ability use code-switching/codemixing because of their lack of competence in one or more of the languages concerned in a given speech situation (Edelsky, Hudelson, Flores, Barkin, Altwerger \& Jilbert 1983). Boztepe (2005: 2), explaining the concept of 'semilingualism', states that "[c]ode-switching has become a part of the performance of the imperfect bilingual ... [S] uch notions about the legitimacy of one language or language variety over another have been the major source of inspiration for the deficit hypothesis in the United States and many other countries". Wardaugh (1992) asserts that prescriptivist monolinguals use expressions such as Spanglish (for the mixing of Spanish and English), Franglais (mixing of French and English), Tex-Mex (mixing English and Mexican Spanish in Texas) to express their disapproval and condemnation of the mixing of codes.

Blanc and Hamers (1989) note that code-mixing, in comparison with code-switching, indicates insufficient linguistic competence. The statement which Wettewe (2009: 8) makes with regard to 'codeswitching' and 'code-mixing' that the two terms "carry pre-conceived assumptions about the competence of bilingual speakers", can be viewed better in light of the negative observations thus discussed above 
on the practices of code-switching and code-mixing. Hence some researchers tend to prefer the terms 'transference' (Clyne, 2003) or 'code-alternation' (Auer, 1984) to 'code-switching' and/or 'codemixing'. In such a context, it is significant, as Bennett-Kastor (2008: 32) records in her account of Irish-English code-switching/code-mixing, her personal observations where speakers switch (as opposed to mixing) languages for "compensatory" purposes, using the components of one language to "substitute for those beyond a person's fluency in the other".

Myres-Scotton argues that "without education to a certain level, it is unlikely a person will be able to speak the linguistic variety associated with Myres-Scotton (1997) contends that for whatever reasons code alternation is practiced, under whatever circumstances and motivations, the political and socioeconomic power in the community". MyresScotton (1997: 11) explains this phenomenon in the following manner:

Code-switching patterns may be indicative of how speakers view themselves in relation to the sociopolitical or cultural values attached to the linguistic varieties used in code-switching. For example, when code-switching is the main in-group medium, its use is evidence that speakers see both codes as salient indices of the values they incorporate in their identities, at least in the social context where it occurs. This is often the case in the Third World, where an indigenous variety is used in a code-switching pattern with the language of the former colonial power (e.g. Baba Malay/English in Singapore (Pakir, 1989), SeSotho/English in South Africa (Khati 1992). 
Parakrama (1995) takes the opposite stance to the above arguments with regard to the practice of code-mixing. He argues that code-mixing, though may be unacceptable on the basis of 'educated' standards, and would therefore cause theoretical problems, stands out as instances of innovative and creative use of language. He points out the critical influence of hegemony on the prevailing negative perspectives on codemixing as a manifestation of lack of education, bad manners or improper control of the two grammars involved. He postulates that communicative strategies such as deliberate code-mixing, far from being degenerative, reveal the reality of language change while being excellent examples of the linguistic creativity of the economically, socially and linguistically subordinate groups. He critiques the elitist attempt to lay down rules of the so-called legitimate, 'safe' language, "often doing violence" to the creativity and identity of those subordinate groups. He states that "[i]t would seem important to try to understand the role that hegemony plays in the reinforcing of such attitudes and in the resisting of others".

Parakrama thus builds up the argument that code-mixing allows the 'uneducated' user of a language "greater freedom in and out of that language (Parakrama, 1995: 119). For example, his standpoint with regard to code-mixed utterances found in conversational interactions carried out in Sinhala is clearly that those utterances "undoubtedly enrich Sinhala speech" (Parakrama, 1995: 120) instead of diluting it. 
... [S]uch (code-mixed) utterances appear to break new ground in creatively combining Sinhala and English, and moreover, do so without violating the spirit of either language (Parakrama, 1995: 119).

He contends that the phenomenon of code-mixing should be viewed in relation to the concept of 'antilanguages', as instances of "resistance to normativity" (Parakrama, 1995: 121). The kind of code-mixing practiced by the popular FM media and their audiences can be viewed in this light as a manifestation of a covert attempt to contest the prevailing elitist norms of linguistic behaviour.

Contrary to the traditional view on code-switching, a considerable number of studies of the recent past have shown that it is the stable bilinguals who code-switch most (for example, Caubet, 2001; McCormick, 2002; Muysken, 2000). Kachru (1983), too, notes that educated Indians with a solid bilingual background use code-mixing in their conversational interactions. Recent studies on linguistic diversification and language alternation have also pointed out that codemixing can be done by individuals who are at different levels of bilingual competence ranging from a minimal to an advanced degree. Associating code-switching with functional bilingualism Bullock and Toribio (2009: xii) use the term 'code-switching' to refer to "the alternating use of two languages in the same stretch of discourse by a bilingual speaker".

Studies viewing code-switching from a social-psychological perspective have noted that the linguistic practice of code-switching/code-mixing 
could be one of the strategies adopted by speakers to adjust the way they speak to match the language preferences of the other interlocutors in a conversational situation (Wei Zhang, 2005; Sachdev and Bourhis, 1990). Trudgill (1992: 7) explains this concept of 'accommodation' as "[t]he process whereby participants in a conversation adjust their accent, dialect or other language characteristics according to the language of the other participant(s)". This concept draws on the Speech Accommodation Theory (or, later, the Communication Accommodation Theory) developed by Howard Giles (Giles \& Smith, 1979). GardnerChloros (2009: 78) presents two possible situations where codeswitching can become quite useful in such instances of communication accommodation, one being when two languages/language varieties carry different social meanings for the participants (in a conversation) coming from different language backgrounds, and the other when there is a mismatch between the participants' levels of competence in the language/s concerned. Thus, as Gardner-Chloros, Charles and Cheshire (2000: 1335) point out, linguistic variation always places the speaker at a conversationally more advantageous position than a monolingual speaker.

Myres-Scotton (1997: 6) remarks that the selection of a "bilingual mode" by a speaker in conversation could be motivated by its appropriateness to his/her intentions. Nevertheless, this selection, as Myres-Scotton points out through the example which follows, is a subconscious one. 
A Senegalese politician who very effectively uses Wolof/French code-switching in his public speeches in Dakar still firmly stated in an interview that he did not mix Wolof and French [Swigart (1994: 185), cited in Myres-Scotton [1997: 6]).

Some of the seminal studies on code-switching situations in different societies have recorded an interdependence between code-switching and the speakers' age. Bentahila and Davies (1983), for instance, have found distinctive differences between the code-switched speech of the older and the younger groups of Arabic-French bilinguals in Morocco. Backus (1996) observes a similar situation in code-switching between Turkish and Dutch in Tilberg, the Netherlands. According to this study, with the increase of contact with monolingual Turkish and Dutch, and thus the advances in proficiency, the patterns of code-switching have changed from intra-sentential switching (or, code-mixing) to inter-sentential switching which indicates higher proficiency in both the languages concerned. In both these occasions, alternation of codes is chosen by their speakers to signal dual membership in groups speaking both languages.

Schmidt (1985), in his study of the use of Dyirbal - a language of the aborigines of Australia, now on the verge of extinction - across generations, notes that switching of codes between different age groups could be consequent on the inadequate competence of some of the participants in the language/s involved in a conversational situation. Schmidt's (1985) study thus becomes a good example of bringing the age factor and linguistic competence together in one study. The younger groups of the speech community in his study tend to resort to excessive 
code-switching between Dyirbal and English as a result of their lack of competence in Dyirbal, thus marking a distinctive difference between the older and the younger speakers of Dyirbal in their frequency in code-switching. Such studies have shown that the more a generation is exposed to urban values and the language associated with those values, the more prone they become to be influenced, sometimes to a vast extent, by those values as well as the language. Whereas the older generations of the societies studied seem to strongly resist such an impact even though the new languages and cultures impose more power on the speech community than their own languages and cultural values.

In migrant situations where the sociolinguistic dominance of one language might gradually cause attrition in the immigrants' first language, thus resulting in linguistic shift by the second generation of immigrants (Myres-Scotton 1997: 6-7).

It has been proposed that through the use of code-switching speakers can define and/or mark a change in social positioning, or 'footing' (Goffman, 1981: 127). Footing', as called by Goffman (1981: 127 cited in Kramsch, 2000: 42) is a speaker's “perception of (one's) role as a participant in an interaction, and in (his/her) alignment to others ... expressed in the way (they) manage the production or reception of utterances". In monolingual speech, one can define his/her footing through the use of register, tone, etc.

The language/language variety a speaker uses may give out different meanings, i.e. indications of the speaker's origin, social class, his/her social values, etc. Similarly, meanings can be attached to the act of 
switching back and forth between languages/language varieties during the same course of conversational interaction (Mesthrie, et. al, 2000). Kachru $(1982 ; 1983 ; 1986)$, too, in his studies on the South Asian experience of English, notes that in the post-colonial societies of South Asia code-mixing denotes modernization and social position. $\mathrm{He}$ observes that speakers' code-mixing with English could indicate power over completely monolingual groups. Kachru (1978) explains this situation with reference to the Indian middle class where speakers codemix local languages with English to signal power, prestige as well as linguistic and social superiority. According to Fasold (1984) too, attitudes towards languages/language varieties could be an important indicator of the significance of language as a social symbol. Auer (1984) reiterates this view when he makes a distinction between the borrowing of single words from another language and code alternation in that, according to him, the alternation between languages is associated with the speaker making it quite obvious to the interlocutors that $\mathrm{s} / \mathrm{he}$ is mixing languages to signal his/her "superior lexical knowledge". In their analyses of the practices of code-switching/code-mixing in various parts of the African sub-continent, language researchers such as Bokamba (1989; 1988), Kamwangamalu (1989) and Akere (1977) have found out that such behavior of crossing over from one language to another in the same stretch of communication is done by individuals or groups for reasons of status and prestige.

On a parallel vein Milroy (1987) as well as Gal (1979) have put forward the idea that one's social network strongly impacts his/her choice of code (cited in Boztepe 2005: 18). Studies conducted by Poplack and her associates on code-switching in French-Canadian communities reveal 
that community peer behavior exercises a stronger impact on the codeswitching habits of an individual than demographic variables or individual linguistic proficiency (Poplack 1988, cited in Myres-Scotton 1997). Treffers-Daller (1992)'s studies on code-switching patterns in Brussels, too, reiterate this feature in that they report code-switching behavior as reflecting intergroup dynamics. Code-switching between Arabic and French among Arabic-French bilinguals in Morocco, as noted by Bentahila and Davies (1992), shows attitudes towards group affiliations.

Several studies on code-switching have shown that the different types of linguistic behavior involved in the practice can bring about positive as well as negative effects on the situation where they occur. In much the same way that code-switching becomes an outcome of a linguistic necessity or is motivated by the need of an individual or a group to express a social identity, it can also be consequent upon the struggle for power between two, or more, linguistic codes (Pujolar, 2001), one distinctly more prestigious than the other/s.

Myers-Scotton and Bolonyai (2001), in the continuation of MyersScotton's argument for a Markedness Theory (1993a), emphasise that the linguistic choices available to a bilingual in a given verbal interaction of code-mixing may contain a variety when used in a context to comply with the accepted rules and conventions of code-switching or code-mixing patterns prevalent in a society, makes that variety the 'unmarked' choice, but when it is used in certain contexts where speakers deviate from convention it gets noted as the 'marked choice'. According to this argument, the unmarked choice is often an index of 
in-group membership, and is thus not used as an out-group mode of communication. For instance, in the Alsace area of France, Alsatian becomes the dominant language in the code-switching events among Alsatian-speaking groups, although French is a frequently spoken language in the area (Gardener-Chloros, 2009). In urban areas in India, where multilingualism is a prominent feature, code-switching/codemixing is prevalent as the unmarked choice for informal communication. In Myres-Scotton's point of view, a dominant language exists even in the unmarked choice of code alternation. In GardnerChloros's (2009: 70) point of view, however, the Markedness Model attaches more importance to the interpretation of conversational participants' intentions, thus placing less prominence on the "creation of meaning by participants within conversations".

Linguists who have studied code-switching from a sociolinguistic perspective have shown how it "contributes in various ways to an understanding of how the individual is articulated with the social" (Gardner-Chloros, 2009: 18). Gardner-Chloros (2009: 41) also argues that sociolinguistic, rather than structural factors influence different subgroups in a community in different ways, resulting in different types of code-switching in the same community. Kachru (1983) reiterates that, out of the different types of linguistic alternation, code-mixings stands out as the higher form of alternation whereas code-mixing is viewed as the lower form.

Bhatia and Ritchie (2004) state that language attitudes, dominance and security determine the qualitative and quantitative properties of language mixing. Though studies on attitudes towards code-switching 
are relatively few, a major part of whatever research that has been conducted in this area hitherto report largely negative attitudes towards the linguistic behaviour concerned. These studies show how language alternation in communication becomes highly stigmatized in many bilingual whatever research that has been conducted in this area hitherto report largely negative attitudes towards the linguistic behaviour concerned. These studies show how language alternation in communication becomes highly stigmatized in many bilingual or multilingual communities in the world (for example, Aikhenvald 2002; Lawson-Sako and Sachdev 2000; Zentella 1997; Chana and Romaine 1984; Bentahila 1983). In communities where prescriptive attitudes towards language and its practice is a dominant feature as well as in societies torn by racial or other inter-group tensions, such attitudes may be resultant in linguistic polarization, thus curtailing the alternation of linguistic codes.

Conversely, the Greek Cypriots in London in Gardner-Chloros, McEntee-Atalianis \& Finnis's (2005) study of their code-switching behaviour, were quite positive in their attitude towards the codeswitching practices among their community. Similarly, the Puerto Rican community in New York, too, consider code-switching as an indication of their affiliation with both the Spanish and English-speaking cultures (Mahootian 2006: 517).

Mahootian (2006) discusses the negative attitudes prevalent among the traditional and older generations of different communities towards linguistic alternation. 
[I]n most communities, code-switching usually has a stigmatized status ... [I]n all bilingual communities one finds that attitudes towards mixed language range from posittive to negative, depending on class, age, education, profession and other social factors. For example, older generations of speakers in a bilingual community typically have a negative response to code-switching and assert that it shows a loss of pride in the home culture and disrespect to the community elders (Mahootian 2006: 516-517).

Mahootian (2006:517) further illustrates on this situation by explaining that, in communities where linguistic variation is considered as selfdemeaning language behavior, younger generations are expected to refrain from code-mixing/code-switching, "at least in the presence of their elders".

In her study of code-switching between Irish and English, Stenson (1990) has observed more intra-sentential switching (i.e. code-mixing) and very few instances of inter-sentential switching. The study revealed that code-mixed utterances usually contained "single lexical items" which, in Bennett-Kastor's (2008: 34) point of view, are distinctly different from "borrowings into Irish". Furthermore, Stenson's (1990: 177-79) study claims that when adjectives appear in Irish code-mixed speech, it is the syntax of the language of the adjective (Irish, in this case) which determines its placement.

Thomason (2001) argues that sometimes speakers might make their own linguistic code by deliberately changing the existing language which they have been using hitherto, thereby developing mixed languages 
which might sometimes fall beyond the intelligibility levels of conventional speakers of the main language. This argument, as cited by Wettewe (2009: 124), "elaborates the no-constraint theory" which suggests that speakers may intentionally bring about changes in the language they speak, and these changes can take place at any level of language.

Chan (1998), referring to the highly westernized culture in Hong-Kong following a British rule for over a century, observes that the mixing between Cantonese and English can be found not only in informal conversational settings but also in interviews on radio and television.

\section{Code-Switching/Code-Mixing in Mass Media}

Transnational research findings have revealed that different genres of mass communication media of the twenty first century has become fertile ground for experimenting with instances of linguistic diversity (Androutsopoulos, 2007). Instances of the marketing of different aspects of bilingualism such as advertising in both print and audio/visual media, code-switching/code-mixing, rapped music, etc. can be found from several different parts of the world including the former colonized countries of Africa, India, and now in Sri Lanka. Androutsopoulos (2007: 207) concedes that "[1]anguage mixing is no doubt a part of the symbolic capital" that profit-oriented commercial media "sells to their audiences".

Sociolinguistically speaking, the linguistic habitus of the mass communication media traditionally constituted of "ideologies and 
practices of monolingualism" (Androutsopoulos 2007:208). In such a context, practices such as code-mixing which are generally associated with informal linguistic behavior, may not have been perceived as legitimately appropriate for use in public discourse. Nevertheless, unlike the national media, the private commercial media, driven by economic factors, seeks diverse strategies to attract audiences, who are its consumers. Thus, the commercial media tends to experiment with their programme formats as well as their use of language, adopting speech styles which have hitherto not been used in media discourse (Androutsopoulos 2007: 208)

\section{Sri Lankan Situation as regards Code-Switching/Code-Mixing}

Long-term contact between English and the indigenous cultures and languages, as characteristic of many parts of the (post)colonial world, has rendered it a common occurrence for different types of language alternation to take place as a means of communication within and among the communities that constitute the society of Sri Lanka (Canagarajah,1995a; 1995b; 1995c). In much the same way that the English-speaking Sinhala/Tamil/Malay natives of the colonial era had to use words from the vernaculars in their English, monolingual Sinhala/Tamil/Malay speakers also had to borrow from the English language in order to discuss matters associated with the British culture. The following excerpt from Shackle (2001:227) explains the linguistic situation in the British colonies of South Asia:

As the result of the long period of British rule, English has become very firmly established in South Asia. Even those with no direct command of English will have been exposed to its indirect influence through the very numerous loan words which have entered all South Asian languages (Shackle 2001:227). 
The practice of code-mixing/code-switching between Sinhala and English, which started with the borrowing of linguistic items from the English language, has today become an effective linguistic strategy in normal, generally informal, bilingual communication in the country. Code-mixing is the norm rather than the exception in urban Sri Lanka today. As Fernando (1982: 354) quite rightly observed approximately four decades ago, there are instances where "... [a] speaker might find it convenient and more natural to use an English term to a fellow bilingual rather than an equivalent Sinhala term". Code-mixing has made such a strong impact in the urban Sri Lankan communication that people of the urban areas seem to have the notion that the use of a Sinhala word in place of a lexical transfer from English might even spoil the colloquial flavor of a conversation and may add to it an artificial character, for, the main function of codeswitching/code-mixing in such occasions is to denote informality.

Even those who fall very low in the cline of bilingualism, thus coming very close to be categorized either as minimal bilinguals or as receiver bilinguals (or passive bilinguals) in terms of their communicative competence in English, might prefer to use a considerable proportion of English words in their day to day conversation, thus engaging in a particular type of intrasentential or 'ragged' switching (Hasselmo, 1961). For instance, terms such as wife, start (a vehicle, as in [sta:t kərənəwa]), pass (an examination, as in [pa:s wenəwa]), sheet (followed by the Sinhala suffix ekə or ekak), etc. are very common and regular lexical transfers from English into conversations carried out in Sinhala.

In Sri Lanka, education does not seem to be a decisive factor in determining the tendency to code-mix. (Mawelle, 2017). The long-term exposure to British colonialism has made it possible for some of the less- 
educated, almost monolingual urban Sinhala/Tamil speakers of the country to use at least a smattering of English, at least in the form of lexical items, in their conversations. Similar to the findings of many studies on linguistic variation from different parts of the world, in Sri Lanka too, speakers codeswitch or code-mix mainly in order to recognize solidarity and in-group identity.

\section{Code-mixing in Popular Sri Lankan Mass Communication Media}

Linguistic diversity is not an uncommon occurrence in the informal mass communication media in Sri Lanka. Despite the ideology and policy of monolingualism in public media discourse on national mass communication media, the private commercial media experiment with several different strategies to attract and retain audiences, which includes new strategies of language use.

In a backdrop where linguistic variation is not encouraged on national broadcasting media which includes the state-owned commercial radio channels, the private commercial radio teams seem to be using linguistic variation, mainly in the form of code-mixing, to be projecting a sense of constructed identity on to their audiences. Bourdieu (1997) postulates that accessing the language with higher prestige is differently distributed in societies. However, even those groups that are altogether denied access to that language, acknowledge the hierarchical relations of linguistic exercise and the legitimacy of a language as the one of prestige and power. 


\section{Conclusion}

Code-alternation is a verbal strategy used by almost all bilinguals throughout the world to colour their speech. Thus it has become an inseparable part of the informal, day-to-day communication of bilinguals. However, it is ironic that the very people who alternate codes in their informal conversations tend to disapprove of this practice when others are engaged in it. Their agitation is more so when this verbal practice is found in the mass communication media, a site which some of them identify with standards of language use. However, though disparaged by language prescriptivists as a substandard form of language use, code-mixing is used in excess by the popular commercial broadcasting media, as a strategy to gain audiences. Excessive codemixing also appears to have become a way of showing their resistance to the hegemonic language practices and the mainstream national radio channels which set and propagate standards for the type of language to be used in media discourse. 


\section{References}

Abdul-Hassan, RS 1988, Variation in the educated spoken Arabic of Iraq: A sociolinguistic study, Unpublished $\mathrm{PhD}$ thesis, University of Leeds.

Abu Bakar, H 2009, 'Code-switching in Kuala Lumpur Malay', Explorations, 9.

Adetuyi, AA Akinghibe, O. Akinola, A. Ogunleye, A., \& Omole, I. 2011, Code mixing and code-switching, Term paper submitted to English Language Department, University of Ibadan, Ibadan.

Aikhenvald, AY 2002, Language contact in Amazonia, Oxford University Press, Oxford.

Akere, F 1977, A Sociolinguistic study of Yoruba speech community in Nigeria: Variation and change in the Ijebu Dialect of Ikorodu, $\mathrm{PhD}$ Thesis, University of Edinburgh.

Alvarez-Caccamo, C 2002, 'Code-switching, class and ideology', Paper presented at the II University of Vigo International Symposium on Bilingualism, University of Vigo, 23-26 October.

Androutsopoulos, J 2007, Bilingualism in the mass media and on the internet, in Bilingualism: A social approach, ed M Heller, Palgrave Macmillan, New York, 207-230.

Appel, R \& Muysken, P 2006, Language contact and bilingualism, Amsterdam University Press. 
Auer, P 1984, 'A conversation analytic approach to code-switching and transfer', in Code-switching: Anthropological and sociolinguistic perspectives, ed, M Heller, Mouton de Gruyter, Berlin and New York, 187-214.

Auer, P 1995, 'The pragmatics of code-switching: a sequential approach', in One speaker, two languages: cross-disciplinary perspectives on code-switching, eds L Milroy \& P Muysken, Cambridge University Press, Cambridge, 115-35.

Auer, P 1999, 'From code-switching via language mixing to fused lects: toward a dynamic typology of bilingual speech', International Journal of Bilingualism, 3(4), 309-332.

Backus A 1996, Two in One: Bilingual Speech of Turkish Immigrants in the Netherlands, Tilburg, Tilburg University Press.

Bennett-Kastor, T 2008, 'Code-mixing in biliterate and multiliterate Irish literary texts, in Estudios Irelandeses, 3, 29-41.

Bentahila, A 1983, Language attitudes among Arabic-French bilinguals in Morocco, Multilingual Matters, Clevedon.

Bentahila, A \& Davies, EE 1983, 'The syntax of Arabic-French codeswitching', Lingua, 59, 301-330.

Bhatia, TK \& Ritchie, WC 2004, The Handbook of Bilingualism, WileyBlackwell.

Blanc, M \&Hamers, JF 1989, Bilinguality and bilingualism, Cambridge University Press, Cambridge.

Bloomfield L, 1927, Language, Holt, New York. 
Bokamba, E 1988, 'Code-mixing, language variation and linguistic theory; evidence from Bantu languages', Lingua 76, 21-62.

Bourdieu, P 1997, Language and symbolic power, Polity Press, Oxford.

Boztepe, E 2005, Issues in code-switching: Competing theories and models, $\quad$ Viewed 25.07.2014, http://journals.tclibrary.org/index.php/tesol/article/viewFile/32/37.

Bullock, BE \& Toribio, J 2009, The Cambridge handbook of linguistic code-switching, Cambridge University Press, Cambridge and New York.

Canagarajah, AS 1995a, 'Use of English borrowings as discourse strategy by Tamil fish vendors', Multilingua 4:1, 5-24.

Canagarajah, AS 1995b, 'The political-economy of code choice in a revolutionary society: Tamil/English bilingualism in Jaffna', reprinted in English in Sri Lanka 2010, eds S Fernando, M Gunasekera \& A Parakrama, SLELTA, 36-65.

Canagarajah, AS 1995c, 'Functions of code switching in the ESL classroom: socializing bilingualism in Jaffna', Journal of Multilingual and Multicultural Development, 16(3), 173-196.

Caubet, D 2001, 'Comment apprehender le code-switching?' in Comment les langues se melangent: code-switching en francophonie, Canut \& Caubet, L'Harmattan, Paris, 21-33. 
Chan, D 1998, 'Functional relations among constructs in the same content domain at different levels of analysis', Journal of Applied Psychology 83 (2), 234-246.

Chana, U \& Romaine, S 1984, 'Evaluative reactions to Punjabi-English code-switching,, Journal of Multilingual and Multicultural Development, 5, 447-453.

Clyne, MG 2003. Dynamics of language contact: English and immigrant languages, Cambridge University Press, Cambridge.

Coupland, N 1984 'Hark, hark, the lark': Social motivations for phonological style-shifting, https://doi.org/10.1016/02715309(85)90007-2.

Edelsky, C, Hudelson, S, Flores, B, Barkin, F, Altwerger, B, \& Jilbert, K 1983, 'Semilingualism and language deficit', Applied Linguistics 4, 122.

Fakeye, DO 2012, 'Motivational Factors for Code Alternation in PreService Teachers' Verbal Communication in Oyo and Ekiti States', Asian Social Science 8 (8), Canadian Center of Science and Education, 149.

Fasold RW 1984, The Sociolinguistics of Society, Basil Blackwell Publisher Ltd., Oxford.

Fernando, C 1982, 'English in Sri Lanka: a case study of a bilingual community', in New Englishes, (ed) J Pride, Newbury House Publishers Inc., Routledge, MA, 188-207. 
Fishman, JA 2000, 'Who speaks what language to whom and when?', Wei, L (ed), The Bilingualism Reader, Routledge, New York, 89-106.

Fong, CW 2011, Functions and reasons for code-switching on facebook by UTAR English-Mandarin Chinese bilingual undergraduates, Unpublished BA Dissertation, Universiti Tunku Abdul Rahman.

Fries, C \& Pike, KL 1949, 'Coexistent phonemic systems', Language 25(1), 29-50.

Gal, S 1979, Language shift: Social determinants of linguistic change in bilingual Austria, Academic Press, New York.

Gardner-Chloros, P 2009, Code-switching, Cambridge University Press, Cambridge.

Gardner-Chloros, P, Charles, R\& Cheshire, J 2000, 'Parallel patterns? A comparison of monolingual speech and bilingual code-switching discourse', Journal of Pragmatics, Special Issue on Code-Switching, 32, 1305-1341.

Gardner-Chloros, P, McEntee-Atalianis, L\& Finnis, K 2005, 'Language attitudes and use in a transplanted setting: Greek Cypriots in London', International Journal of Multilingualism, 52-80.

Giles, H \& Smith, P 1979, 'Accommodation theory: optimal levels of convergence', Language and Social Psychology, (eds) H Giles \& R. St. Clair, Blackwell, Oxford, 45-66.

Goffman, E 1981, Forms of talk, University of Pennsylvania Press, Philadelphia. 
Grosjean, F 1982, Life with two languages, Harvard University Press, Cambridge, MA.

Hamam, M 2011, 'Text vs. Context: Some examples of the rhetorical value of the diglossic code-switching in Arabic - A Gumperzian approach, Pragmatics 21(1), International Pragmatics Association, 4167.

Hasselmo, N 1961, American Swedish: A study in bilingualism, Unpublished PhD dissertation, Harvard University.

Haugen, EI 1956, Bilingualism in the Americas: A bibliography and research guide, University of Alabama Press, Alabama.

Heredia, RR \& Brown, JM (forthcoming) 'Code-switching', in The encyclopedia of linguistics, Fitzroy Dearborn Publishers, Chicago, viewed 24 June 2011.<http://www.tamiu.edu/ rheredia/switch.htm>.

Holmes, J, 2001, Introduction to sociolinguistics, Longman, London.

Hudson, RA 1980, Sociolinguistics, Cambridge University Press, Cambridge, UK.

Hymes, D 1974, Foundations in sociolinguistics: An ethnographic approach, Longman, London.

Jakobson, R, 1990, On Language, Jakobson Foundation, Inc., USA.

Kachru, BB 1978, 'Code-mixing as a communicative strategy', in International dimensions of bilingual education, ed J Alatis, Georgetown University Press, Washington, 107-24. 
Kachru, BB 1983, The Indianization of English Language in India, Oxford University Press, Oxford.

Kachru, BB 1986, The alchemy of English: the spread, functions and models for non-native Englishes, Pergamon Press, Oxford.

Kamwangamalu, N 1989, Code-Mixing and Modernization, World Englishes 8(3).

Kim, E 2006, 'Reasons and Motivations for Code-mixing and codeswitching', EFL, 4(1).

Khati, T 1992. Intra-lexical switching or nonce borrowing? Evidence from SeSotho-English performance, in Language and Society in Africa, ed. R K. Herbert, University of Witwatersrand Press, Johannesburg, 181-196.

Kramsch, C 2000, Language and culture, Oxford University Press, Oxford.

Lawson-Sako, S \& Sachdev, I 2000, 'Codeswitching in Tunisia: Attitudinal and behavioural dimensions', Journal of Pragmatics 32 (9), 1343-1361.

LePage, RB \& Tabouret-Keller, A 1985, Acts of identity: Creole-based approaches to ethnicity and language, Cambridge University Press, Cambridge.

Leopold, WF 1939, Speech development of a bilingual child, Northwestern University Press, Evanston, IL

Li DCS, 1999/1997, 'Cantonese-English code-switching research in Hong-Kong: A Y2K review', World Englishes 19 (3), 305-322. 
Mawelle, I J 2017, Code-Mixing as a Radical Conversational Strategy on Popular Sinhala Medium FM Radio: A Deconstructive Study, Unpublished PhD Thesis, Faculty of Graduate Studies, University of Colombo.

McClure, E 1977, 'Aspects of code-switching in the discourse of bilingual Mexican-American children', in Linguistics and anthropology, ed M Saville-Troike, Georgetown University Press, Washington, DC, 93-115.

McCormick, K 2002, Language in Cape Town's District Six, Oxford University Press, Oxford.

Mesthrie, R, Swann, J, Deumert, A \& Leap, W 2000, Introducing sociolinguistics, Edinburgh University Press, Edinburgh.

Milroy, L 1987, Language and social networks, Basil Blackwell, Oxford.

Muysken, P 2000, Bilingual speech: A typology of code-mixing, Cambridge University Press, Cambridge, UK and New York.

Myers-Scotton, C 1993, Social motivations for code-switching: Evidence from Africa, Clarendon Press, Oxford.

Myers-Scotton, C 1997, Code-switching, The Handbook of Sociolinguistics, ed. F Coulmas, Basil Blackwell Publishers, Oxford.

Myers-Scotton, C \& Bolonyai, A 2001, 'Calculating speakers: codeswitching in a Rational Choice Model', Language in Society 30, 1-28.

Pakir, A 1989, Linguistic alternates and code selection in Baba Malay, World Englishes 8:3, 379-388. 
Parakrama, A 1995, De-hegemonising language standards: learning from (post)colonial Englishes about English, Macmillan Press, London.

Poplack, S 1988, 'Contrasting patterns of code-switching in two communities', in Code-switching: Anthropological and sociolinguistic perspectives, ed M. Heller, Mouton de Gruyter, Berlin, 215-245.

Poplack, S \& Meechan, M 1995, 'Patterns of language mixture: Nominal structure in Wolof-French and Fongbe-French bilingual discourse', in One speaker, two languages: Cross-disciplinary perspectives on code-switching, edsL Milroy \& P Muysken, Cambridge University Press, Cambridge, 199-232.

Pujolar i Cos, J 2001, Gender, heteroglossia and power.A sociolinguistic study of youth culture, Mouton de Gruyter, Berlin/New York.

Ronjat, J 1913, Le development du langage observe chez un enfant bilingue, Champion, Paris.

Sachdev, I \& Bourhis, RY 1990, 'Bi- and multilingual communication', in The handbook of language and social psychology, eds H Giles \&P Robinson, John Wiley \& Sons, Chichester, New York, 293-308.

Schmidt, A 1985, Young people's Djirbal, Cambridge University Press, Cambridge.

Sebba, M 2005, 'Towards a typology and analytical framework for mixed language texts', Talk delivered at ISB5, Barcelona, March.

Shackle, C 2001, 'Speakers of South Asian languages' in Learner English: a teacher's guide to interference and other problems, eds M Swan \& B Smith, Cambridge University Press, Cambridge, 227-243. 
Sridhar SN \& Sridhar K, 1980, The syntax and psycholinguistics of bilingual code-mixing, Canadian Journal of Psychology 34, 407-416.

Stenson, N 1990, 'Phrase structure congruence, government, and IrishEnglish code-switching', in The syntax and semantics Vol.23 ed. R. Hendrick, Academic Press, San Diego, 167-197.

Swann, S, Deumert, A, Lillis, T \& Mesthrie, R 2004, A dictionary of sociolinguistics, Edinburgh Thomason, SG 2001, Language Contact, Edinburgh University Press, Edinburgh. University Press, Edinburgh.

Swigart, L Cultural creolisation and language use in post-colonial Africa: the case of Senegal, https://doi.org/10.2307/1160978

Tabouret-Keller, A 1997, Les enjeux de la nomination des langues, Louvain-la-Neuve, Peeters.

Treffers-Daller, J 1992, French-Dutch code-switching in Brussels: Social factors explaining its disappearance, Journal of Multilingual and Multicultural Development 13 (1-2), 143-156.

Trudgill, P 1992, Introducing language and society, Penguin, London.

Wardhaugh, R 1992, An Introduction to Sociolinguistics, Blackwell, Oxford.

Weinreich, U 1953, Languages in contact, Mouton, The Hague.

Wettewe, CD 2009, Sinhala English code mixing in Sri Lanka, Netherlands Graduate School of Linguistics, viewed 21 March, 2011. http://www. lotpublications. nl 
Wei Zhang, 2005, 'Code-choice in bidialectal interaction: the choice between Putonghua and Cantonese in a radio phone-in program in Shenzhen', Journal of Pragmatics 37(iii), 355-375.

Wray, A, Trott, K. \& Bloomer, A, 1998, Projects in linguistics, Arnold, London.

Zentella, AC 1997, Growing up bilingual: Puerto Rican children in New York, Blackwell, Oxford/Malden, MA. 